\title{
LITERATURA E INFÂNCIA: A INTERTEXTUALIDADE NA PERSPECTIVA DO LEITOR
}

\author{
LITERATURE IN CHILDHOOD: INTERTEXTUALITY FROM THE READER'S PERSPECTIVE \\ LITERATURA E INFANCIA: LA INTERTEXTUALIDAD EN LA PERSPECTIVA DEL LECTOR
}

Renata Junqueira de Souza ${ }^{1}$

Claudia Leite Brandão

${ }^{1}$ Doutora em Letras pela UNESP. Docente do Programa de Pós-Graduação em Educação da Universidade Estadual Paulista Júlio de Mesquita Filho (UNESP), Presidente Prudente, SP, Brasil.

${ }^{2}$ Doutoranda em Educação pela Universidade Estadual Paulista Júlio de Mesquita Filho (UNESP), Presidente Prudente, SP, Brasil.

Resumo: Este trabalho fundamenta-se na relevância do convívio das crianças com a literatura infantil, por meio do ato de ler, contar e/ou ouvir as histórias, seja ainda pela possibilidade de formação humana. Assim, o artigo objetiva refletir sobre a importância da literatura infantil para apropriação de saberes socialmente construídos pelos pequenos leitores. Para isto, considerando que o gênero conto é repleto de personagens que encantam as crianças, seleciona-se a obra $O$ carteiro chegou, de Janet Ahlberg \& Allan Ahlberg, para demonstrar a inserção do real e/ou insólito, bem como as relações intertextuais com os contos maravilhosos presentes no enredo.

Palavras-chave: Literatura; Infância; Intertextualidade.

Abstract: This work is based on the importance of children's exposure to literature, through the act of reading, telling and hearing stories, for the possibility of human formation. This article therefore reflects on the importance of children's literature for the appropriation of socially constructed knowledge by young readers. Considering that the genre of children's story is full of characters that enchant children, the work The jolly postman by Janet Ahlberg \& Allan Ahlberg was selected, to demonstrate the insertion of the real and/or unusual, as well as the intertextual relations with the wonderful tales present in the plot.

Keywords: Literature; Childhood; Intertextuality.

Resumen: Este trabajo se fundamenta en la relevancia de la convivencia de los niños con la literatura infantil, por medio del acto de leer, contar y oír las historias, siendo aún de esta manera la posibilidad de formación humana. Así, el artículo objetiva reflexionar sobre la importancia de la literatura infantil para apropiación de saberes socialmente construidos por los pequeños lectores. Para ello, considerando que el género cuento está repleto de personajes que encanta a los niños, se selecciona la obra El cartero llegó, de Janet Ahlberg \& Allan Ahlberg, para demostrar la inserción de lo real e insólito, así como las relaciones intertextuales con los cuentos maravillosos presentes en la trama.

Palabras clave: Literatura; La infancia; Intertextualidad. 
Somos construídos tanto pelos muitos textos que atravessam culturalmente os nossos corpos, quanto pelo que vivemos. (PAULINO; COSSON, 2009, p. 69).

O presente artigo objetiva refletir sobre a relevância da literatura infantil para a apropriação de saberes socialmente construídos pelas crianças, a partir da concepção da força formadora da literatura infantil na infância, por meio do ato de ouvir, contar e/ou ler histórias literárias. Neste sentido, nos apoiamos nas palavras de Chartier $(2008$, p. 129) quando diz que "[...] não se deve esquecer a literatura, pois as leituras infantis não têm como objetivo apenas distrair ou habituar as crianças a utilizarem esses textos, mas é através dessas leituras que se forma a personalidade, a inteligência, o caráter [...]."

Para a teoria histórico-cultural, a criança é um ser social em constante desenvolvimento e o seu processo de formação e a sua constituição humana ultrapassam as condições biológicas, ou seja, o seu desenvolvimento cognitivo, afetivo e social se dará por meio das suas vivências e experiências sociais e culturais. Nas palavras de Girotto e Souza,

O pensamento, a imaginação, a linguagem, a atenção, a memória, a apreciação estética e outras capacidades humanas, como representar por meio de diferentes linguagens (desenhar, pintar, modelar, dançar, dramatizar, etc.); aprender atos enunciativos; apropriar-se do ler e escrever, do falar de acordo com o padrão culto; dentre outras qualidades ou formas de conduta especificamente do humano, contribuem, assim, para e com o processo de aprendizagem e do desenvolvimento do psiquismo infantil (GIROTTO; SOUZA, 2016, p. 12).

Nesta perspectiva, concordamos que se as crianças, desde a infância, conviverem com a presença da literatura, poderão ampliar os percursos da sua formação humana. Em consonância com isso, afirmamos que o contato com as histórias promoverá novas relações com a linguagem, contribuindo para o desenvolvimento do processo de aprendizagem e socialização.

Segundo Coelho (1995), a literatura infantil conceitua-se como uma abertura para a formação de uma nova mentalidade, além de ser um instrumento de emoções, diversão ou prazer, desempenhada pelas histórias [...] "que objetiva a educação integral da criança, proporcionando-Ihe a educação humanística e ajudando-a na formação de seu próprio estilo" (COELHO, 1995, p. 05).

Nessa direção, a inserção das crianças na cultura escrita pode ser mediada pela leitura e/ou contação de histórias realizadas pelos educadores no ambiente escolar. Segundo Girotto e Souza,

A escuta literária retira o homem de seu próprio tempo, de seu tempo individual, cronológico, histórico e o projeta simbolicamente para um instante que não pode ser medido por não ser constituído por uma única direção. A abertura para o exercício da imaginação simbólica se realiza pelo viés da educação literária, sendo tal exercício iniciado muito antes de a criança aprender a falar, a contar, a usar sua voz (GIROTTO; SOUZA, 2016, p. 29).

Nesta perspectiva, além das práticas de leitura literária, as crianças, ao terem contato com o objeto livro, ou seja, por meio do manuseio das páginas, desenvolvem o sensorial. Para Bajard (2014, p. 10), "os métodos ativos preconizam que as aprendizagens fundamentais sejam construídas dentro de uma prática de linguagem. Assim como a criança aprende a 
falar falando, aprende a andar andando, aprenderá a língua escrita através do seu uso". Neste contexto, Coelho aponta que:

[...] no ato de leitura, através do literário, dá-se o conhecimento da consciência de mundo ali presente. Assimilada pelo leitor, ela começa a atuar em seu espírito (e conforme o caso a dinamiza-lo no sentido de certa transformação...). Mas, para que essa importante assimilação se cumpra, é necessário que a leitura consiga estabelecer uma relação essencial entre o sujeito que lê e o objeto que é o livro lido (COELHO, 2000, p. 51).

Nesta mesma linha de raciocínio, concebemos as histórias literárias como caminhos de inserção ao diversificado e plural mundo da cultura humana, que atraem a atenção e a curiosidade das crianças. Ademais, o conto é um dos gêneros que proporciona o deslumbramento de lugares mágicos e até mesmo reais, alinhando o insólito ao real.

Segundo Calvino (2007, p. 10), "os clássicos são livros que exercem uma influência particular quando se impõem como inesquecíveis e também quando se ocultam nas dobras da memória, mimetizando-se como inconsciente coletivo ou individual".

Assim, prosseguimos com uma breve discussão sobre os contos primordiais e a intertextualidade, a posteriori, finalizamos com a contextualização da obra O carteiro chegou, de Janet Ahlberg \& Allan Ahlberg, para demonstrar as relações entre o real e/ou insólito, tecidos em literaturas para crianças.

\section{CONTOS TRADICIONAIS: UMA POSSIBILIDADE PARA OS INTERTEXTOS}

Na França do século XVII, a literatura infantil deu seus primeiros passos, por meio da publicação da primeira coletânea de contos infantis, Contos da Mãe Gansa (1697), de Charles Perrault. Embora, a princípio, Perrault não tencionasse escrever para crianças, o resgate dos contos transmitidos oralmente, graças à memória do povo, possibilitou-lhe a chance de "provar a equivalência de valores ou de sabedoria entre os antigos greco-latinos e os antigos nacionais e, com esse material redescoberto, divertir as crianças, principalmente as meninas, orientando sua formação moral" (COELHO, 2003, p. 77).

Mais tarde, despontaram, ainda na França, La Fontaine; na Alemanha, os irmãos Grimm e na Dinamarca, Hans Christian Andersen. Vale destacar que, no Brasil, a consolidação da literatura infantil ganhou força em 1970 com a renovação da indústria cultural. Diante de um contexto social de mudanças políticas e tentativas de restauração da estabilização e da ordem da pátria, a literatura para crianças encontrou meios, no mercado de produção, de firmar-se como caráter literário e consolidar um público leitor (LAJOLO; ZILBERMANN, 2007).

Sabemos que a melhor e maior representação da literatura infantil está nos contos clássicos, embora haja distinção em relação à problemática que fundamenta a diegese nos contos maravilhosos, contos de fadas e contos de encantamentos (COELHO, 2003), como se percebe, usamos de ambas as nomenclaturas para tratar deste acervo que caracteriza a literatura infantil.

Contudo, segundo Coelho (2000), é evidente que a relação estrutural, em ambos os contos, tem invariantes fixas e, deste modo, há sempre uma personagem tipo ou caractere 
que, por algum desígnio, é levada a uma viagem, ainda que, neste percurso, surja um conflito, desafio ou obstáculo a ser superado. Apesar disto, a personagem vence o desafio com o auxílio de um poder mágico ou mediador e, finalmente, consegue conquistar seu objetivo.

Essa repetição das estruturas é, para o pequeno leitor, cativante porque supre suas necessidades de apreciação de situações conhecidas, uma vez que, para ele, conhecer os fatos antemão aos seus acontecimentos é motivo de prazer e segurança e de domínio das situações. No geral, propiciar-Ihe entendimento quanto às suas relações conflituosas, desabrochando, assim, o gosto das crianças em ouvir inúmeras vezes a mesma história.

Como vimos, a repetição é um aspecto importante dos contos; além de invariantes estruturais, as formas discursivas também se assemelham, todavia os contos contemporâneos trazem características novas, haja visto que, hoje, seus leitores, ainda que pequenos, têm vivências diferentes, assim é preciso inovar e (re)significar o mundo.

Nesse sentido, o objeto livro, no mundo atual, disputa atenção com diferentes artefatos, como computadores, tabletes, celulares, etc. Torna-se, então, comum que as narrativas modernas dialoguem com outros textos, formando-se por meio de relações intertextuais.

Para Koch e Elias (2014), o reconhecimento da presença de outros textos em uma produção escrita é decorrente dos conhecimentos do leitor e, especialmente, de seu repertório de leitura. Logo, a compreensão e a produção de sentido do texto ocorrem por meio da relação intrínseca de leituras passadas.

As autoras destacam, ainda, que embora haja, na nova produção, ecos dos textos fontes "o deslocamento de enunciados de um contexto para outro, indiscutivelmente, provocará alteração de sentidos" (KOCH; ELIAS, 2014, p. 78-79).

Em conformidade com isso, Nicolajeva e Scott reiteram que:

A intertextualidade pressupõe que o leitor participe ativamente do processo de decodificação; em outras palavras, é o leitor quem faz a conexão intertextual. Isso significa que a alusão só faz sentido se o leitor estiver familiarizado com o hipotexto (o texto a que se alude) (NICOLAJEVA; SCOTT, 2011, p. 295).

Vejamos quais os conhecimentos que o pequeno leitor deve e pode acionar durante a leitura de $\mathrm{O}$ carteiro chegou, bem como as possibilidades de revisitar outras narrativas.

\section{CONTEXTUALIZANDO A OBRA O CARTEIRO CHEGOU}

Para avançar na discussão da presença da literatura infantil na vida das crianças, selecionamos para a análise o livro O carteiro chegou, de Janet Ahlberg \& Allan Ahlberg, do gênero conto contemporâneo. A escolha se deu pelo fato da narrativa criar possibilidades do pensamento real e/ou insólito, bem como a intertextualidade com os contos maravilhosos tradicionais.

Nesta direção, consideramos que a obra ecoa o conceito de livro para a infância de Rocha e Machado (2011, p. 91), a qual postula que "um livro é uma caixinha de surpresas para uma criança. Cada vez que vira uma página, ela encontra uma coisa diferente. O livro desperta curiosidade, vontade de entrar naquele universo de faz de conta [...]". 
O livro O carteiro chegou segue o formato de caixinha de surpresa, já que, a cada folhear, algo novo surge em suas páginas, desde os personagens até os recursos utilizados para a apresentação dos mesmos. A obra, publicada no Brasil pela Companhia das Letrinhas, traz a seguinte apresentação: "Este livro é como a sacola do Carteiro: Vem cheio de cartas de verdade, com envelope e tudo para você abrir e ler! São cartas que o Carteiro levou para alguns personagens que você conhece de outras histórias" (AHLBERG; AHLBERG, 2007, não paginado).

Como podemos perceber, a apresentação do livro contextualiza o que o leitor encontrará na obra, possibilitando a ativação do conhecimento prévio sobre as histórias que já estão presentes no repertório dos pequenos e quando se adentram na narrativa vivenciam a materialidade das cartas apresentadas na obra.

Figura 1 - Capa do Livro - O Carteiro Chegou

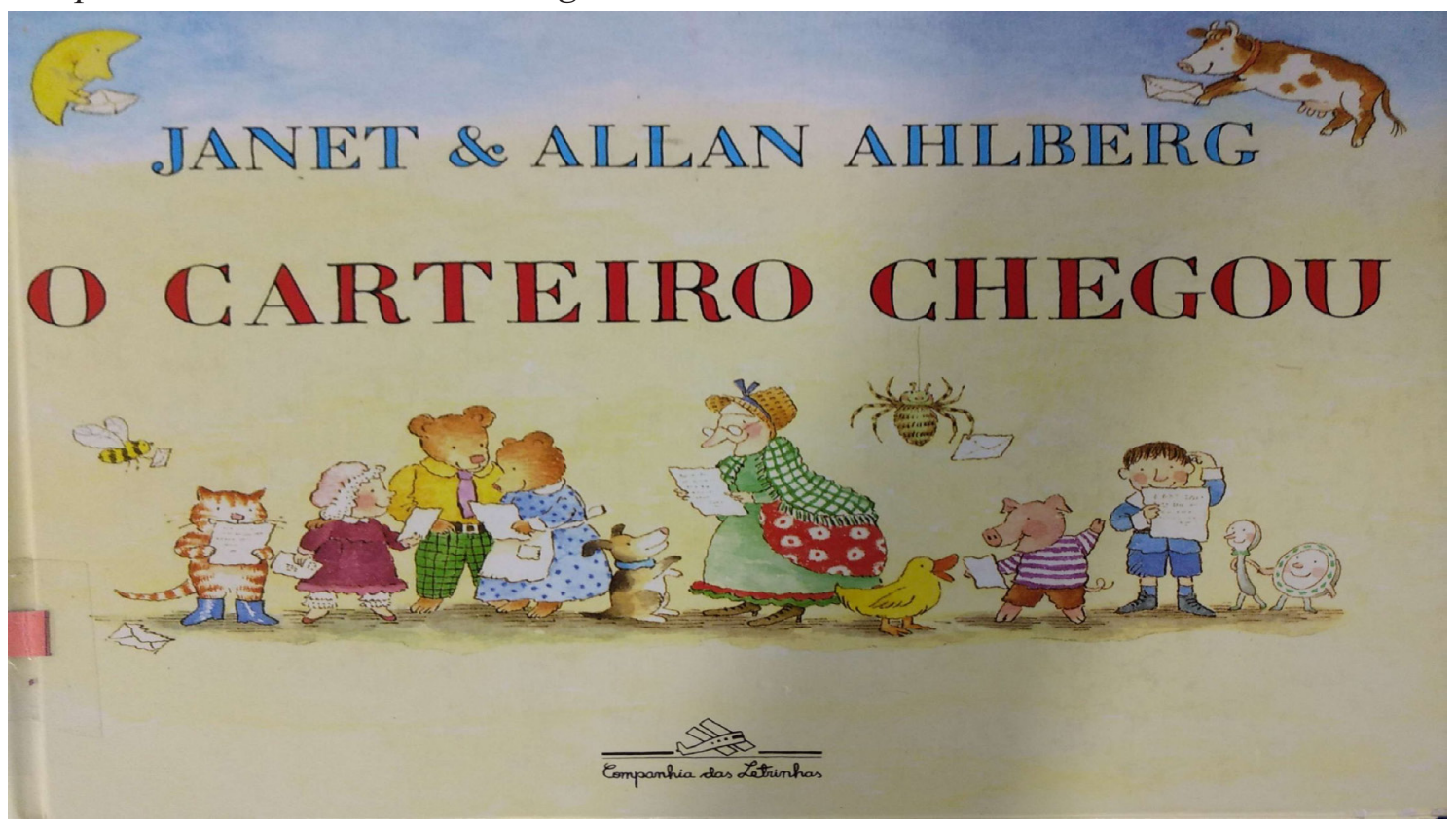

Fonte: $A H L B E R G$; $A H L B E R G$ (2007)

A história de O carteiro chegou é um conto que rompe com a frase inicial "Era uma vez ..." dos contos primordiais, a entrada do texto é marcada pela descrição do primeiro trajeto do carteiro para entregar uma carta enviada por Cachinhos Dourados aos Três Ursos.

No primeiro ato, a narrativa já marca a situação principal da história, a entrega das correspondências, mas também sinaliza o possível final, visto que, além de pedir desculpas, Cachinhos Dourados convida o ursinho para sua festa de aniversário. "P.S: Gostaria muito que o ursinho viesse à minha festa de aniversário" (AHLBERG; AHLBERG, 2007, não paginado).

Coelho (2000, p. 68) afirma que o conto possui um motivo central - conflito, situação ou acontecimento - estruturado em poucas páginas. "Tudo no conto é condensado, a efabulação se desenvolve em torno de uma única ação ou situação; a caracterização das personagens é breve; a duração temporal é curta [...]".

O carteiro instaura-se como protagonista do enredo, é ele quem articula toda a história com as entregas das correspondências. Em suma, a cada entrega, um novo personagem dos 
contos de fadas aparece. Essa situação direciona o pequeno leitor à formulação de perguntas que poderão ser respondidas após a leitura de cada carta, tendo novas perguntas reformuladas.

O surgimento dos personagens dos contos de fadas possibilita que as crianças despertem os seus conhecimentos prévios sobre as narrativas. Segundo Kleiman (1999, p. 13), "a compreensão de um texto é um processo que se caracteriza pela utilização do conhecimento prévio: o leitor utiliza na leitura o que ele já sabe, o conhecimento adquirido ao longo de sua vida."

Nesta mesma perspectiva, Solé (1998) evidencia que o leitor constrói o sentido do texto, compreendendo-o a partir de suas próprias experiências, expectativas e conhecimentos prévios.

\begin{abstract}
Para ler necessitamos, simultaneamente, manejar com destreza as habilidades de decodificação e aportar ao texto nossos objetivos, ideias e experiências prévias; precisamos nos envolver em um processo de previsão e inferência contínua, que se apoia na informação proporcionada pelo texto e na nossa própria bagagem, em um processo que permita encontrar evidência ou rejeitar as previsões e inferências antes mencionadas (SOLĖ, 1998, p. 23).
\end{abstract}

Na obra em análise, a presença de intertextos assegura, no ato de ler, momentos de inferência para ativar os conhecimentos prévios das crianças. Para Girotto e Souza (2010), o trabalho com os textos pode partir das estratégias de leituras que se organizam em: conhecimento prévio, conexão, visualização, questionamento, inferência, sumarização e síntese. Dessa forma, as autoras esclarecem que estratégias de leituras são "[...]habilidades utilizadas pelos leitores para compreenderem o que leem e de conhecerem a maneira como formulam seus pensamentos, descobrindo os processos mentais de entendimento de um texto" (GIROTTO; SOUZA, 2010, p. 54).

Assim sendo, a história apresenta um encadeamento de ações com imagens e texto que dialogam, muito do texto não verbal introduz, sutilmente, as personagens que compõem a narrativa. Logo, as crianças, ao questionarem, fazerem conexões, inferirem, discutirem e debaterem sobre as personagens que são apresentadas diante de cada entrega do carteiro, configuram a inter-relação entre autor-texto-leitor.

Por se entretecer na forma de conto, o texto segue uma estrutura semelhante aos contos de fadas, com uma narrativa linear. O enredo é apresentado em rimas e o narrador situado na terceira pessoa, ele conta o que viu por meio do discurso direto e diálogos. A narrativa marca as situações do real e/ou insólito existente na história.

Cabe ressaltar que, para analisar o insólito nessa obra, escolhemos a definição de Batista (2011) que traz como mote: o que não acontece habitualmente; incomum; extraordinário; estranho. Nesse sentido, a constituição da dimensão ficcional apresenta o caráter de insólito, uma vez que um carteiro entregando correspondências no mundo de personagens fantásticos é algo irreal, anormal e de fato extraordinário. Na perspectiva de Colomer (2003, p. 71), a narrativa demonstra "a projeção de um elemento comum em um mundo extraordinário".

Já Coelho (2000) completa essa afirmação ressaltando que muito desse universo literário infantil é dotado de poderes mágicos, tendo as fronteiras entre o real e o imaginário destruídas, surge, então no mundo contemporâneo, um revisitamento dos contos tradicionais como forma de o homem se reinventar e se redescobrir. 
De certo modo, seguindo a leitura linear do texto, a criança tem possibilidades de relembrar os diferentes contos de fadas e conhecer e/ou reconhecer os diversos tipos de correspondências que existem na nossa sociedade.

Como já vimos, são várias cartas colocadas em envelopes: carta de pedido de desculpas de Cachinhos Dourados para os Três Ursos; panfleto de propaganda para a Bruxa malvada da história de João e Maria; cartão postal de João para o gigante (João e o Pé de Feijão); carta comercial para Cinderela formalizando a publicação da sua história; carta de despejo dos advogados de Chapeuzinho Vermelho para o Lobo e o cartão de aniversário da Chapeuzinho Vermelho para Cachinhos Dourados.

É interessante perceber que a história se inicia com Cachinhos Dourados como remetente da primeira carta e finaliza com a mesma personagem, porém no papel de destinatária.

Além disso, no encerramento do conto, não temos a frase "E foram felizes para sempre", no entanto a história termina com a presença de novos personagens fantásticos na festa de Cachinhos Dourados e, logo após, o carteiro "[...] volta sorrindo para casa pra descansar - e tomar chá" (AHLBERG; AHLBERG, 2007, não paginado).

Essa circularidade da obra também está presente na vinheta final, que mostra o carteiro, sentado em uma poltrona lendo sua correspondência, ou seja, depois de entregar as cartas para toda comunidade dos contos de fadas, é a vez dele também se atualizar lendo o que o correio lhe trouxe, restaurando a ideia de atemporalidade presentes nas narrativas mágicas.

Ainda sobre o desfecho, há continuação da intertextualidade presente com as personagens dos clássicos, anteriormente, apresentadas e outros que surgiram apenas no término do enredo, como: Pinóquio, Três Porquinhos, Patinho Feio, entre outros.

Figura 2: Intertextualidade na obra O Carteiro Chegou

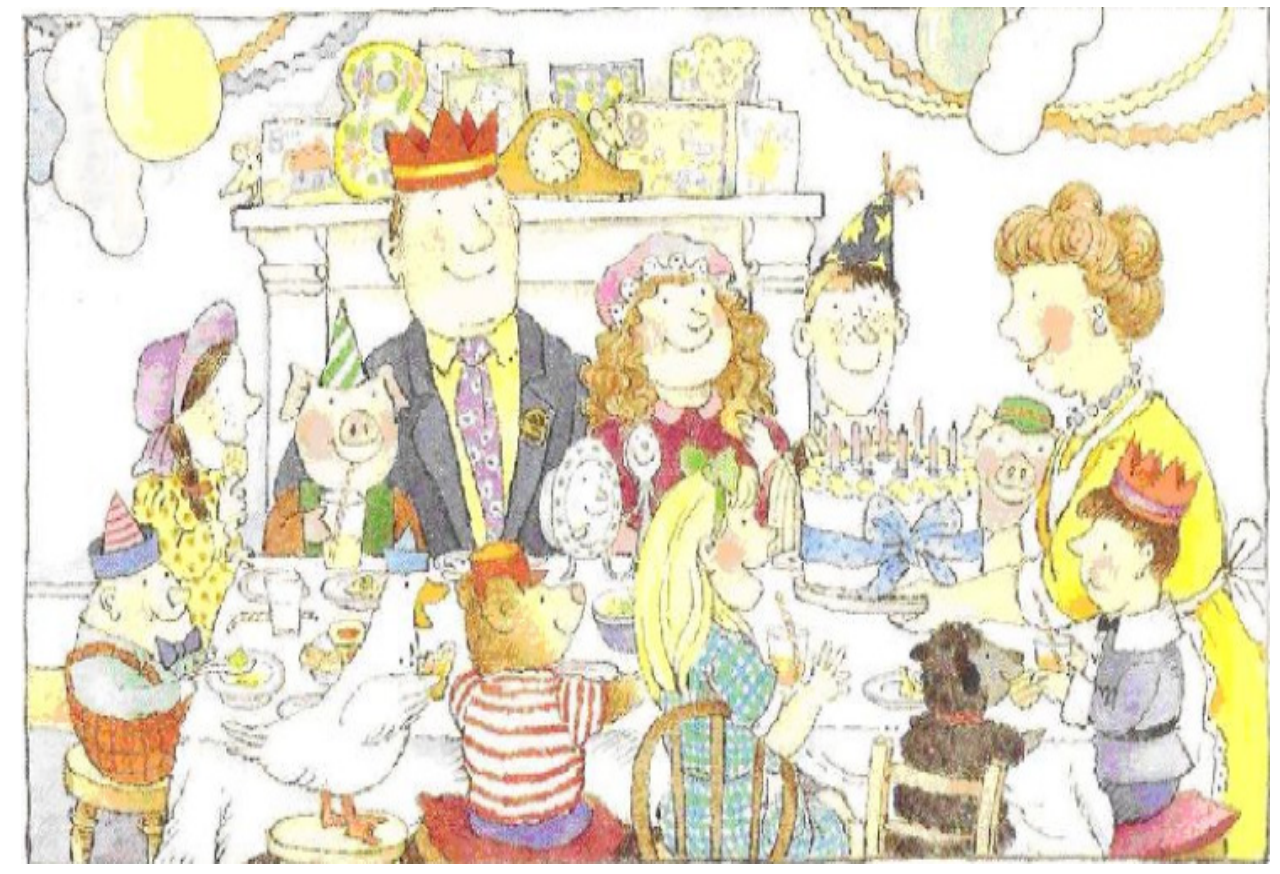

Fonte: AHLBERG; AHLBERG (2007) 
No geral, além de a história inserir novos conhecimentos sobre o uso social das correspondências em nossa sociedade, a obra se torna chamativa pelo fato de as cartas estarem inseridas materialmente em envelopes dentro do conto, trazendo literalidade às formas textuais com outros fins. Outro fator marcante na narrativa é a intertextualidade presente no texto, evento que desencadeia a ativação do conhecimento prévio e as conexões para ser realizadas por meio dos clássicos infantis.

Dessa maneira, temos a clareza que o conhecimento prévio é ativado a partir de saberes que o leitor já possui em relação ao que está lendo, contribuindo para produção de sentidos, enquanto que a conexão remeteria a lembranças de outros textos lidos (livros, filmes), neste caso, em especial, aos contos clássicos.

Finalmente, a obra literária em discussão pode ser apreendida como diálogo entre a história e a cultura do passado e do presente, como diz Arena (2010, p. 17), "o leitor pequeno não terá boas chances de atribuição de sentido a uma obra se não estabelecer com ela e com os eventos culturais, de hoje e de outrem, relações contextuais de natureza cultural". Assim, por meio das outras vozes que ecoam do texto, o leitor acumulará conhecimentos socialmente construídos e experiências de cunho artístico.

Por fim, asseguramos que em $O$ carteiro chegou, a faculdade humana da imaginação é envolvente, pois, após as leituras das cartas, os leitores poderão, como atividade criadora, refletir sobre a continuidade dos contos primordiais e ir muito além do tradicional desfecho "E foram felizes para sempre".

\section{ALGUMAS CONSIDERAÇÕES}

Para ler necessitamos, simultaneamente, manejar com destreza as habilidades de decodificação e aportar ao texto nossos objetivos, ideias e experiências prévias; precisamos nos envolver em um processo de previsão e inferência contínua, que se apoia na informação proporcionada pelo texto e na nossa própria bagagem, em um processo que permita encontrar evidência ou rejeitar as previsões e inferências antes mencionadas (SOLĖ, 1998, p. 23).

Com este texto, pretendemos mostrar que, se a literatura infantil for integrada ao processo de desenvolvimento das crianças, as histórias literárias poderão contribuir para a sua formação e constituição humana, seja no aspecto cognitivo, afetivo e social. Nesta perspectiva, os contos têm em suas narrativas importantes situações marcadas pelo insólito e/ou real que encantam as crianças, despertando o interesse pelo ler, ouvir e/ou contar, ativando o sensório.

A narrativa literária estabelece espaços de diálogos "inter" e "intra" textuais e o conto de $O$ carteiro chegou apresenta uma importante sinalização da intertextualidade na forma direta, deixando pistas para que o leitor relembre dos clássicos que conhece ou, ainda, se não conhece, busque conhecer esses personagens maravilhosos e narrativas tão encantadoras, sempre em uma perspectiva de ampliação de conhecimentos.

Assim, é possível estender a compreensão de que a participação das crianças nas conexões e nos entendimentos das histórias são elos primordiais no processo de aprendizagem da leitura. Para Girotto e Souza (2010), essas práticas dialógicas "[...] permitem que as crianças 
avancem nas suas conexões, pois no geral, elas começam a fazer conexões texto-texto para elementos mais óbvios da história, como personagens e problemas".

\section{REFERÊNCIAS}

AHLBERG, J.; AHLBERG, A. O carteiro chegou. Tradução: Eduardo Brandão. São Paulo: Companhia das letrinhas, 2007.

ARENA, D. B. A literatura infantil como produção cultural e como instrumento de iniciação da criança no mundo da cultura escrita. In: SOUZA, R. J. de. (et al.). Ler e compreender: estratégias de leitura. Campinas: Mercado de Letras, 2010. p.13 - 44.

BAJARD, E. Da escuta de textos à leitura. 2. ed. São Paulo: Editora Cortez, 2014.

BATISTA, E. O mito em Guimarães Rosa: travessias insólitas. In: Congresso Internacional ABRALIC. Anais...Curitiba: UFPR, 2011. Disponível em: http://www.abralic.org.br/anais/?p=18. Acesso em: março de 2017.

CALVINO, I. Por que ler os clássicos. São Paulo: Companhias das letras, 2007.

CHARTIER, A. M. Que leitores queremos formar com a literatura infanto-juvenil? In: PAIVA, A. (et al.). Leituras literárias: discursos transitivos. Belo Horizonte: Ceale: Autêntica, 2008.

COELHO, N. N. Panorama Histórico da Literatura Infantil. 5. ed. São Paulo: Ática, 1995.

COELHO, N. N. Literatura Infantil: teoria, análise, didática. 1. ed. São Paulo: Moderna, 2000.

COELHO, N. N. O conto de fadas: símbolos, mitos e arquétipos. São Paulo: DCL, 2003.

COLOMER, T. A formação do leitor literário: narrativa infantil e juvenil atual. Tradução: Laura Sandroni. São Paulo: Global, 2003.

GIROTTO, C. G. G. S.; SOUZA, R. J. de. Estratégias de leitura: para ensinar alunos a compreender o que leem. In: SOUZA, R. J. de. (et al.). Ler e compreender: estratégias de leitura Campinas: Mercado de Letras, 2010. p. 45 -114.

GIROTTO, C. G. G. S.; SOUZA, R. J. de. Práticas de leitura na infância: desatando os nós da formação de ouvintes a leitores. In: GIROTTO, C. G. G. S.; SOUZA, R. J. de. Literatura e Educação Infantil: livros, imagens e práticas de leitura. Campinas. Mercado de Letras, 2016 (vol. 1), p. 11-38.

KLEIMAN, A. Texto e leitor: aspectos cognitivos da leitura. Campinas: Pontes, 1999.

KOCH, I. V.; ELIAS, V. M. Ler e compreender os sentidos do texto. 3. ed. São Paulo: Contexto, 2014.

LAJOLO, M.; ZILBERMAN, R. Histórias \& histórias. 7. ed. São Paulo: Ática, 2007.

NIKOLAJEVA, M.; SCOTT, C. Livro Ilustrado: palavras e imagens. São Paulo: Cosac Naify, 2011.

PAULINO, G.; COSSON, R. Letramento literário: para viver a literatura dentro e fora. In: ZILBERMANN, R.; RÖSING, T. M. (Org.). Escola e leitura: velha crise, novas alternativas. São Paulo: Global, 2009.

ROCHA, R.; MACHADO, A. M. Contando histórias, formando leitores. Campinas, SP: Papirus 7 Mares, 2011.

SOLÉ, I. Estratégias de leitura. Tradução: Cláudia Schilling. Porto Alegre: Artmed, 1998. 
Artigo recebido em: 08/01/2018 Aprovado em: 02/04/2018

Contato para correspondência:

Renata Junqueira de Souza.

E-mail: recellij@gmail.com 